
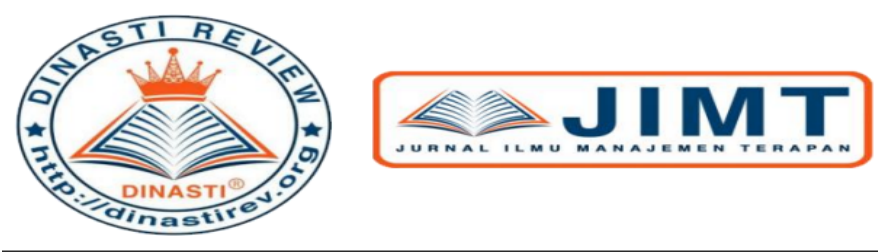

+62 878-9658-6407 087896586407

https://dinastirev.org/JIMT editor@dinastirev.org

\title{
PENGARUH BAGI HASIL PEMBIAYAAN MUDHARABAH PEMBIAYAAN MUSYARAKAH DAN PEMBIAYAAN MURABAHAH TERHADAP PROFITABILITAS
}

Teguh Arifianto ${ }^{1)}$, Apollo ${ }^{2)}$

1) Jurusan Akuntansi, Fakultas Ekonomi dan Bisnis, Universitas Mercu Buana, Jakarta, Indonesia

2) Jurusan Akuntansi, Fakultas Ekonomi dan Bisnis, Universitas Mercu Buana, Jakarta, Indonesia

\begin{tabular}{|c|c|}
\hline $\begin{array}{l}\text { ARTICLE INFORMATION } \\
\text { Received: } 14 \text { April } 2020 \\
\text { Revised: } 20 \text { April } 2020 \\
\text { Issued: } 27 \text { April } 2020 \\
\text { Corresponding Author: } \\
\text { Teguh Arifianto } \\
\text { E-mail: } \\
\text { teguh2309@gmail.com } \\
\text { Apollo@mercubuana.ac.id }\end{array}$ & $\begin{array}{l}\text { Abstrak: Penelitian ini bertujuan untuk menguji } \\
\text { pengaruh pembiayaan mudharabah, pembiayaan } \\
\text { musyarakah dan pembiayaan murabahah terhadap } \\
\text { profitabilitas pada bank umum syariah yang terdaftar di } \\
\text { Otoritas Jasa Keuangan (OJK) dengan menggunakan } \\
\text { rasio Return On Equity (ROE). Sampel yang digunakan } \\
\text { dalam penelitian ini adalah Purposive Sampling. Sumber } \\
\text { data yang digunakan dalam penelitian ini adalah metode } \\
\text { deskriptif dengan pendekatan kuantitatif dan metode } \\
\text { analisisnya adalah Uji Asumsi Klasik, Uji Kelayakan } \\
\text { Model dan Uji Hipotesis. Hasil penelitian ini } \\
\text { menunjukan bahwa Pembiayaan Mudharabah positif dan } \\
\text { signifikan dengan koefisien regresi 2,362 dan } \\
\text { signifikansi (0,026 < 0,05). Pembiayaan Musyarakah } \\
\text { positif dan tidak signifikan dengan koefisien regresi } \\
\text { 0,699 dan signifikansi (0,491 > 0,05). Pembiayaan } \\
\text { Murabahah negatif dan signifikan dengan koefisien } \\
\text { regresi -4,776 dan signifikaansi (0,000<0,05) } \\
\text { Kata Kunci: Pembiayaan Mudharabah, Pembiayaan } \\
\text { Musyarakah, Pembiayaan Murabahah dan Profitabilitas }\end{array}$ \\
\hline
\end{tabular}

\section{PENDAHULUAN}

Bank syariah sebagai lembaga intermediasi antara pihak investor yang menginvestasikan dananya di bank kemudian Bank Syariah menyalurkan dananya kepada pihak lain yang membutuhkan dana. Perbankan syariah nasional dalam dekade terakhir terus menunjukan pertumbuhan yang cukup menggembirakan yang tercermin dari volume usaha yang terus tumbuh, dana investasi dan dana titipan masyarakat serta penyaluran pembiayaan yang terus meningkat. 
Perbankan syariah mengalami pertumbuhan positif dengan peningkatan rata-rata sekitar $33.2 \%$ dalam 10 tahun terakhir, terlihat dengan adanya perlambatan pertumbuhan volume usaha dalam perkembangan di tiga tahun terakhir sehingga akhir tahun 2014 hanya mencatatkan pertumbuhan sebesar $12 \%$

Perbankan syariah mengalami berbagai macam isu strategis dan berdampak terhadap pengembangan bank syariah nasional dan menjadi perhatian para pemangku kepentingan. Isu-isu strategis dalam berkembangnya industri perbankan syariah di Indonesia, antara lain: belum selarasnya visi dan kurangnya koordinasi antar pemerintah dan otoritas dalam pengembangan perbankan syariah, modal yang belum memadai dan skala industri bank yang masih kecil serta efisiensi yang rendah, biaya dana yang mahal berdampak pada keterbatasan segmen pembiayaan, produk yang tidak variatif dan pelayanan yang belum sesuai ekspektasi masyarakat, kuantitas dan kualitas sumber daya manusia (SDM) serta teknologi informasi (TI) yang belum memadai dan mendukung pengembangan produk dan layanan. Kerumitan persoalan tersebut menimbulkan dampak terhadap kepercayaan masyarakat tentang keberadaan bank syariah diantara lembaga keuangan konevensional.

\section{KAJIAN PUSTAKA}

\section{Teori Keagenan (Agency Theory)}

Menurut Jensen dan Meckling (1976) teori keagenan muncul karena ada kontrak kerja atas persetujuan bersama yang terjadi antara Principal dan Agent. Agent adalah pihak yang menjalankan tugas dari principal, sedangkan Principal yang memiliki wewenang untuk mengatur kerja agent. Jika kedua belah pihak memiliki hubungan baik maka ada alasan kuat bahwa agent tidak akan bertindak diluar kepentingan principal. Principal dapat membatasi perbedaan antara kedua belah pihak dengan menetapkan insentif yang sesuai untuk agent dan menimbulkan biaya monitoring yang dibuat untuk membatasi aktifitas menyimpang dari agent. Agent dibayar untuk menjamin bahwa dia tidak akan mengambil tindakan yang akan merugikan principal. Namun sering kali agent bertindak diluar kehendak yang berakibat tidak maksimalnya dan tidak konsisten penghasilan yang diterima. Menurut Gurbaxani dan Kemerer (1989), ini terjadi karena pertama, tujuan principal dan agent tidak konsisten satu dengan yang lainnya (ketidaksesuaian tujuan) dan kedua principal tidak dapat memonitor dengan sempurna tindakan dan informasi dari agent (asimetris information). 
Permasalahan penyimpangan-penyimpangan yang terjadi pada Bank Syariah juga dapat diatasi dengan mengoptimalkan skema bagi hasil yang ditetapkan. Tidak optimalnya skema bagi hasil akan menimbulkan kecurigaan bank dan membuat bank meningkatkan biaya pengawasan dan verifikasi dalam pembiayaan. Skema bagi hasil ini berupa pemenuhan harapan yang diinginkan nasabah dan pihak bank. Dengan pengoptimalan skema bagi hasil pihak nasabah diharapkan dapat memberi informasi yang benar mengenai karakter dan usahanya sehingga dapat menekan masalah adverse selection dan moral hazard. Karena nasabah harus dapat menjalankan usahanya dengan upaya yang maksimal untuk dapat memaksimalkan pendapatan yang dihasilkan agar sesuai dengan harapan pihak bank dan nasabah.

\section{METODE PENELITIAN}

Pada penelitian ini penulis mengambil data yang bersumber dari situs www.ojk.go.id ataupun dari masing-masing bank umum. Sampel yang digunakan berjumlah 30 sampel dari 6 bank selama 5 tahun dengan teknik purposive sampling. Analisis data yang terdiri dari statistik deskriptif dan Uji t.

\section{HASIL DAN PEMBAHASAN}

\section{Tabel 1. Hasil Uji Statistik Deskriptif}

\begin{tabular}{|c|c|c|c|c|c|}
\hline \multicolumn{6}{|c|}{ Descriptive Statistics } \\
\hline & $\mathrm{N}$ & Minimum & Maximum & Mean & Std. Deviation \\
\hline Mudharabah & 29 & 188351 & 3703697 & 1270029,62 & 1004936,263 \\
\hline Musyarakah & 29 & 532542 & 20192427 & 7096448,00 & 6913401,466 \\
\hline Murabahah & 29 & 526897 & 36233737 & 13440335,83 & 11851352,170 \\
\hline ProfitabilitasROE & 29 &, 004 & ,134 & ,05214 & ,034846 \\
\hline Valid N (listwise) & 29 & & & & \\
\hline
\end{tabular}

Berdasarkan hasil pengujian statistik deskriptif dapat dijelaskan bahwa :

a. $\quad \mathrm{N}=29$, sampel yang terdiri dari 6 Bank Umum Syariah selama 5 periode yaitu 20132017. 1 data yang dihilangkan karena memiliki nilai yang jauh berbeda dari keseluruhan data.

b. Pembiayaan Mudharabah

Bank Syariah sebagai penyedia seluruh modal (Shahibul Maal) atau yang diamanati sebagai pengelola (Mudharib) telah menyalurkan Pembiayaan Mudharabah dengan nilai terkecil (minimum) sebesar Rp.188.351 yaitu BCA Syariah pada tahun 2014 dan nilai terbesar 
(maksimum) sebesar Rp.3.703.697 yaitu Bank Syariah Mandiri pada tahun 2013. Rata-rata (mean) pembiayaan mudharabah sebesar 1.270.029,62 menunjukan bahwa bank dapat diandalkan nasabah sebagai pengelola maupun penyedia modal karena menyalurkan pembiayaan mudharabah dengan baik. dengan standar deviasi sebesar 1.004.936,263.

c. Pembiayaan Musyarakah

Bank syariah sebagai mitra nasabah telah menyalurkan Pembiayaan Musyarakah dengan nilai terkecil (minimum) sebesar Rp.532.542 yaitu Bank BCA Syariah pada tahun 2013 dan nilai terbesar (maksimum) sebesar Rp.20.192.427 yaitu Bank Muamalat pada tahun 2015. Rata-rata (mean) pembiayaan musyarakah sebesar 7.096.448,00 menunjukan bahwa nasabah dapat mengandalkan kinerja Bank Syariah sebagai mitranya. dengan standar deviasi sebesar 6.913.401,466.

d. Pembiayaan Murabahah

Bank Syariah dengan sistem jual beli telah melakukan transaksi dengan nasabah melalui Pembiayaan Murabahah yang memiliki nilai transaksi terkecil (minimum) sebesar Rp.526.897 yaitu Bank Panin Syariah pada tahun 2015 dan nilai transaksi terbesar (maksimum) sebesar Rp.36.233.737 yaitu Bank Syariah Mandiri pada tahun 2017. Rata-rata (mean) transaksi yang telah dilakukan antara Bank Syariah dengan nasabah sebesar 13.440.335,83. dengan standar deviasi sebesar 11.865.483,612.

e. Profitabilitas (ROE)

Dari hasil pengujian deskriptif variabel profitabilitas mempunyai nilai terkecil (minimum) sebesar 0,004 yaitu Bank Panin Syariah pada tahun 2017 dan nilai terbesar (maksimum) sebesar 0,134 yaitu Bank Syariah Mandiri pada tahun 2013. Sedangkan nilai rata-rata (mean) sebesar 0,05214 menunjukan bahwa Bank Syariah dapat berhasil menghasilkan laba dari ketiga pembiayaan yang dilakukan Bank Syariah. Dengan standar deviasi sebesar 0,034846.

Tabel 2. Hasil Uji Signifikansi Parameter Individual (Uji-t)

Coefficients $^{\mathrm{a}}$

\begin{tabular}{|c|c|c|c|c|c|c|}
\hline \multirow{2}{*}{\multicolumn{2}{|c|}{ Model }} & \multicolumn{2}{|c|}{$\begin{array}{l}\text { Unstandardized } \\
\text { Coefficients }\end{array}$} & \multirow{2}{*}{$\begin{array}{c}\text { Standardized } \\
\text { Coefficients } \\
\text { Beta }\end{array}$} & \multirow[t]{2}{*}{$t$} & \multirow[t]{2}{*}{ Sig. } \\
\hline & & $B$ & Std. Error & & & \\
\hline \multirow{4}{*}{1} & (Constant) & $-2,083$ & 3,233 & &,- 644 & ,525 \\
\hline & Mudharabah & ,891 & ,377 & ,556 & 2,362 & ,026 \\
\hline & Musyarakah &, 175 & ,250 & ,144 & ,699 & ,491 \\
\hline & Murabahah & $-1,071$ & ,224 & $-1,128$ & $-4,776$ &, 000 \\
\hline
\end{tabular}

a. Dependent Variable: ProfitabilitasROE

Berdasarkan hasil uji statistik t pada tabel di atas sebagai berikut : 
a. Pada tabel diatas nilai $\mathrm{t}_{\text {hitung }}$ sebesar 2,362 dan nilai $\mathrm{t}_{\text {tabel }}$ sebesar 2,05553 dan sig $0,026<0,05$. Dengan demikian bahwa pembiayaan mudharabah memiliki hubungan positif dan signifikan. Maka $\mathrm{H}_{1}$ diterima karena pembiayaan mudharabah berpengaruh signifikan terhadap profitabilitas (ROE).

b. Pada tabel diatas nilai $t_{\text {hitung }}$ sebesar 0,699 dan nilai $t_{\text {tabel }}$ sebesar 2,05553 dan sig $0,491>0,05$. Dengan demikian bahwa pembiayaan musyarakah memiliki pengaruh positif dan tidak signifikan. Maka $\mathrm{H}_{2}$ ditolak karena pembiayaan musyarakah tidak berpengaruh signifikan terhadap profitabilitas (ROE).

c. Pada tabel diatas nilai $\mathrm{t}_{\text {hitung }}$ sebesar $-4,776$ dan nilai $\mathrm{t}_{\text {tabel }}$ sebesar 2,05553 dan sig $0,000<0,05$. Dengan demikian bahwa pembiayaan murabahah memiliki hubungan negatif dan signifikan. Maka $\mathrm{H}_{3}$ diterima karena pembiayaan murabahah berpengaruh signifikan terhadap profitabilitas (ROE).

1. Analisis Regresi Berganda

Berdasarkan hasil pengolahan data, persamaan regresi yang dihasilkan adalah sebagai berikut :

$$
\begin{gathered}
Y=\alpha+\beta_{1} X_{1}+\beta_{2} X_{2}+\beta_{3} X_{3} \\
R O E=-2,083+0,891 X_{1}+0,175 X_{2}-1,071 X_{3}
\end{gathered}
$$

a. Nilai konstanta sebesar -2,083 menyatakan bahwa jika variabel independen (Pembiayaan Mudharabah, Pembiayaan Musyarakah, dan Pembiayaan Murabahah) bernilai nol, maka besarnya profitabilitas (ROE) sebesar -2,083.

b. Nilai koefisien regresi Pembiayaan Mudharabah sebesar 0,891. Hal ini menunjukkan bahwa setiap perubahan jumlah pembiayaan Mudharabah sebesar 1 maka profitabilitas akan meningkat sebesar 0,891 dengan asumsi variabel lainnya tetap.

c. Nilai koefisien regresi Pembiayaan Musyarakah sebesar 0,175. Hal ini menunjukkan bahwa setiap perubahan jumlah pembiayaan Musyarakah sebesar 1 maka profitabilitas akan meningkat sebesar 0,175 dengan asumsi variabel lainnya tetap.

d. Nilai koefisien regresi Pembiayaan Murabahah sebesar -1,071. Hal ini menunjukkan bahwa setiap perubahan jumlah pembiayaan Murabahah sebesar 1 maka profitabilitas akan meningkat sebesar -1,071 dengan asumsi variabel lainnya tetap.

\section{KESIMPULAN DAN SARAN}

1. Kesimpulan

Berdasarkan hasil analisis dan pengujian mengenai pengaruh pembiayaan mudharabah, pembiayaan musyarakah, dan pembiayaan murabahah terhadap profitabilitas, maka dapat diperoleh kesimpulan sebagai berikut :

a. Pembiayaan mudharabah berpengaruh terhadap profitabilitas, yang berarti pembiayaan mudharabah ini mampu dalam menghasilkan laba dari pengelolaan modal yang dilakukan oleh pengelola.

b. Pembiayaan musyarakah tidak berpengaruh terhadap profitabilitas, yang berarti pembiayaan musyarakah tidak mempengaruhi profitabilitas karena nasabah melakukan tindakan atau kebijakan yang dapat menguntungkan pribadi. 
c. Pembiayaan murabahah berpengaruh terhadap profitabilitas. Karena pada pembiayaan ini bank bisa menentukan margin keuntungan terhadap barang yang akan dibeli oleh nasabah dan bank pula dapat membuat barang yang dibeli sebagai barang jaminan terhadap nasabah apabila ia telat bayar untuk menutupi seluruh angsuran.

2. Saran

Saran untuk penelitian selanjutnya adalah sebagai berikut :

a. Sebaiknya menggunakan jumlah sampel yang lebih banyak dan menggunakan data baru. Agar penelitian memberikan hasil yang lebih relevan dan akurat.

b. Dapat mengembangkan produk-produk unggulan dan mengenalkan produk-produk lainnya berdasarkan kebutuhan nasabah.

c. Mencari variabel independen lain yang tidak di jelaskan pada penelitian ini, menambah periode penelitian dan juga sampel penelitian.

\section{DAFTAR RUJUKAN}

Accounting And Auditing Organization For Islamic Financial Institutions (AAOIFI). (2017). Shari'ah Standards. Manama, Kingdom of Bahrain.

Anjani, Rivalah dan Hasmarani, Maulidiyah Indira. (2016). Pengaruh Pembiayaan Mudharabah, Musyarakah dan Murabahah Terhadap Profitabilitas BPRS di Indonesia Periode 2012 2015. Syariah Paper Accounting. FEB UMS, ISSN 2460-0784.

Annual Report Bank BCA Syariah. (2013-2017). Diakses April 2019 http://www.bcasyariah.co.id/

Annual Report Bank BNI Syariah. (2013-2017). Diakses April 2019 https://www.bnisyariah.co.id/id-id/

Annual Report Bank BRI Syariah. (2013-2017). Diakses April 2019 https://www.brisyariah.co.id/

Annual Report Bank Mandiri Syariah. (2013-2017). Diakses April 2019 https://www.mandirisyariah.co.id

Annual Report Bank Muamalat. (2013-2017). Diakses April 2019 https://www.bankmuamalat.co.id/

Annual Report Bank Panin Syariah. (2013-2017). Diakses April 2019 https://www.paninbanksyariah.co.id/

Apollo., Doktoralina, C. (2019). The contribution of strategic management accounting in supply chain outcomes and logistic firm profitability. Journal Uncertain Supply Chain Management, 7(2), 145-156.

Apollo. (2004). Pecking Order Or Trade-Off Hypothesis Evidence on the Capital Structure (A Study Mining Companies In Indonesia). Jurnal Akuntansi Auditing dan Keuangan, BALANCE, 71-82. 
Chalifah, Ela., Sodiq, Amirus. (2015). Pengaruh Pendapatan Mudharabah dan Musyarakah Terhadap Profitabilitas (ROA) Bank Syariah Mandiri Periode 2006-2014. Jurnal Ekonomi Syariah STAIN Kudus/Vol.3 No.1.

Fatwa Dewan Syari'ah Nasional NO:04/DSN-MUI/IV/2000 tentang Murabahah.

Fatwa Dewan Syari'ah Nasional-Majelis Ulama Indonesia NO:115/DSN-MUI/IX/2017 tentang Mudharabah.

Fatwa Dewan Syari'ah Nasional NO:08/DSN-MUI/IV/2000 tentang Musyarakah.

Ghozali, Imam. (2016). Aplikasi Analisis Multivariete dengan program IBM SPSS 23. Semarang: Badan Penerbit Universitas Diponegoro.

Hariyanti, Diyah Santi. (2016). Analisa Kontribusi Pembiayaan Musyarakah, Murabahah, dan Ijarah Terhadap Profitabilitas (ROE) Pada Bank BNI Syariah. Jurnal Ekonomi Arthavidya/ Vol.18 No.1.

Kristianto, Bagas Alif (2016). Pengaruh Pembiayaan Mudharabah, Musyarakah, Murabahah Terhadap Profitabilitas Pada BRI Syariah di Indonesia (Studi Empiris pada BRI Syariah di Indonesia Tahun 2011-2014).

Nurhayati, Sri dan Wasilah. (2013). Akuntansi Syariah di Indonesia, Salemba Empat, Jakarta.

Oktriani, Yesi. (2011). Pengaruh Pembiayaan Musyarakah, Mudharabah dan Murabahah Terhadap Profitabilitas. Jurnal Universitas Siliwangi.

Otoritas Jasa Keuangan. (2016). Standar Produk Musyarakah dan Musyarakah Mutanaqishah. Jakarta.

Permata, R. I. D., Yaningwati, F., Zahroh Z.A. (2014). Analisis Pengaruh Pembiayaan Mudharabah dan Musyarakah Terhadap Tingkat Profitabilitas (Return On Equity). Jurnal Administrasi Bisnis/Vol.12 No.1 Juli 2014.

Ramadhani, D, P., Reinissa (2014) Pengaruh Pembiayaan Mudharabah, Musyarakah, dan Murabahah terhadap Profitabilitas Bank Syariah Mandiri. Jurnal Ilmiah Mahasiswa FEB Universitas Brawijaya/Vol.3 No.2 2014.

Sari, Mulya. (2015). Pengaruh Pembiayaan Mudharabah, Pembiayaan Musyarakah, dan Pembiayaan Murabahah Terhadap Profitabilitas Pada Bank Syariah Mandiri dan Bank Muamalat Indonesia. Jurnal Akunida/Vol 2 No.1.

Sari, Dewi Wulan., Anshori, Mohamad Yusak (2017) Pengaruh Pembiayaan Murabahah, Istishna, Mudharabah, dan Musyarakah Terhadap Profitabilitas (Studi Pada Bank SyariahdiI Indonesia Periode Maret 2015 - Agustus 2016). Accounting and Management Journal, Vol. 1, No. 1, July 2017.

Septiani, Atika (2017) Analisis Pengaruh Pembiayaan Mudharabah, Pembiayaan Musyarakah, dan Pembiayaan Murabahah Terhadap Profitabilitas Bank Umum Syariah yang Terdaftar di Bank Indonesia. Ak.-IBS, 2017. 
Wiroso. 2011. Produk Perbankan Syariah dilengkapi dengan UU perbankan Syariah dan Kodifikasi Produk Bank Indonesia. Diakses 07 Maret 2018 dari http://iaiglobal.or.id/v03/materi-publiksi. 